\title{
Oil mixing behavior after an oil spill: identification conflicts of different fingerprints
}

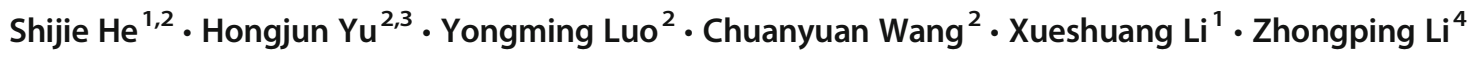

Received: 30 October 2017 / Accepted: 9 January 2018 / Published online: 22 January 2018

(C) Springer-Verlag GmbH Germany, part of Springer Nature 2018

\begin{abstract}
Clearing up whether spilled oil is mixed or not can strengthen the accuracy of oil spill identification. In the present study, the biomarkers in spilled oil samples were detected. The weathering modes of different types of diagnostic ratio and carbon isotope values of individual $n$-alkanes were also analyzed. The results showed that the diagnostic ratios of steroids, terpenes and aromatics, and weathering characteristics of carbon isotope composition $\left(\delta^{13} \mathrm{C}\right)$ of individual $n$-alkanes supported the idea that Dalian oil spill emerged from a single oil source. Furthermore, commonly used diagnostic ratios of $n$-alkanes indicated that the Dalian oil spill had undergone the oil mixing process. The different identifying outcomes indicate that some kinds of $n$-alkane-rich substance (such as oil dispersants) were mixed in the Dalian spilled oil and interfered with the routine diagnosis ratios of $n$-alkanes.
\end{abstract}

Keywords Dalian oil spill $\cdot$ Mixing spilled oils $\cdot$ Diagnostic ratios $\cdot$ Carbon isotope composition of individual $n$-alkanes $\cdot$ Oil spill identification

\section{Introduction}

Offshore oil pollution is mainly caused by various human activities such as the exploration and development of offshore oil; the breakdown of the hull structure, stranding, or fire explosion of an oil tanker; and the collision of an oil tanker. Some oil pollution, having resulted from such accidents, gave abominable impacts to marine environment. For example, the Deep Water Horizon oil spill happened in 2010 in the Gulf of Mexico and released nearly 500 million barrels of crude oil into the ocean, polluting an area of $9900 \mathrm{~km}^{2}$ (Wei et al. 2014).

\section{Responsible editor: Philippe Garrigues}

Shijie He

yantaienv@126.com

1 Coast Institute, Ludong University, Yantai 264025, People's Republic of China

2 Yantai Institute of Coastal Zone Research, Chinese Academy of Sciences, Yantai 264003, People's Republic of China

3 Deep Sea Base Management Center, State Oceanic Administration, Qingdao 266061, People's Republic of China

4 Key Laboratory of Petroleum Resources Research, Institute of Geology and Geophysics, Chinese Academy of Sciences, Lanzhou 730000, People's Republic of China
The spill still affects the ecology of the Mexican coast (Goldstein et al. 2011; Hayworth et al. 2015).

From a global perspective, large-scale oil spills (the oil spill quantity is more than $700 \mathrm{t}$ ) continued to decrease recently. Although there were only two large oil spills in 2015, the number of small-scale oil spills (the oil spill quantity is less than $7 \mathrm{t}$ ) has continuously increased (ITOPF 2016) in the past few years. The small-scale oil spill accidents are more difficult to be concealed and pose new challenges for responsible search and identification of these oil spills. Statistics show that oil and its products spilled into the China Sea are about $1.2 \times 10^{5} \mathrm{t} /$ year since the start of this century (Guo 2004). The average concentration of the oil in the China Sea has reached the value of $0.055 \mathrm{mg} / \mathrm{L}$, whereas the oil pollution in some offshore areas is deteriorating (Guo 2004). Several large-scale oil spills have occurred in China's coastal waters in recent years. For instance, Xingang's 7-16 oil spill accident in Dalian, which took place on July 16, 2010, spilled about $1500 \mathrm{t}$ of oil, while the pollution caused by the spill spread to an area of around $427 \mathrm{~km}^{2}$. In addition, the 19-3 oil spill in Penglai and the "11-22" oil pipeline leakage accident in Qingdao have not only harmed the marine ecological environment but have also shown many adverse effects on the coastal socio-economic development (Guo et al. 2013; Liu et al. 2015). An in-depth study on 
the migration and transformation of different types of oil in different areas is not only beneficial to predicting the development and impact of oil spill events (Brandvik et al. 2006) but will also help to prepare the emergency response, mitigation, remediation, and remediation measures for any new oil spill (Fingas 2015).

The application significance of oil spill identification is to correctly identify the oil source. Relative oil spill identification indices are always affected by the oil weathering and oil mixing processes (Betti et al. 2011; Fingas 2015). Under certain circumstances, particular spilled oil with mixed sources usually involves multiple parties at the same time. In such a case, it is necessary to straighten out the relevant liability (Kvenvolden et al. 1995) and clear the fingerprinting measures, which can be applied to trace the oil sources directly related to the mixed oil spill event (Christensen and Tomasi 2007; Yim et al. 2011).

The complexity of various weathering processes in water environment, especially the marine environment, makes the oil mixing process more likely to occur. In order to ensure the accuracy of oil's identification, the on-site sampling of the oils must be obtained rapidly or in a timely manner. In this case, oil mixing process might not be analyzed correctly and satisfactorily if there are mixtures that oil came from different sources. Therefore, the properties and indices of the miscellaneous oil samples collected from different sampling points or in different times are different and difficult to interpret, thus resulting in ambiguity as compared to oil spill events which have only a single oil source. In this paper, the authors have collected and analyzed oil spill indicators of the "7-16" oil spill, which occurred in Dalian, and discussed whether it was a mixed spill oil or not.

\section{Sample collection and tests}

\section{Sample collections}

A series of continuously weathered oil dregs were collected from the oil-polluted seawater in the Dalian Bay on the 0th, 1st, 10th, 60th, 90th, and 120th day after the oil spill. The samples were marked as DL-1, DL-2, DL-3, DL-4, DL-5, and DL-6, respectively. After collection, the oil samples were placed in a prewashed amber bottle using a solvent-scrubbed scoop and stored in a freezer until further analysis.

\section{Extraction, fractionation, and instrumental analysis}

The $n$-alkane and biomarkers in spilled oil samples were detected using gas chromatography-mass spectrometry (GCMS). Additionally, carbon isotope values of individual $n$-alkanes were also analyzed using gas chromatography-thermal conversion/thermal cracking furnace and isotope mass spectrometry (GC-IRMS).

\section{Gas chromatography-mass spectrometry}

The GC-MS test was performed at Marine Ecology Research Center, First Institute of Oceanography of the State Oceanic Administration, Qingdao, China.

\section{Reagents and sample preparation}

The reagents were TEDIA (Hexane, 95\%, HPLC/SPECTRO), sodium sulfate $\left(\mathrm{Na}_{2} \mathrm{SO}_{4}\right.$, anhydrous, GR for analysis, from Tianjin Kermal Chemical Reagents Co., Tianjin, China), and $0.22 \mu \mathrm{m}$ nylon filter. Deuterated tetracosane (Sigma LTD, Castleford, UK), $5 \alpha$-androstane (Sigma LTD), and deuterated terphenyl (J\&K Scientific LTD, Beijing, China) were used as internal standards.

Anhydrous $\mathrm{Na}_{2} \mathrm{SO}_{4}$ was placed in a muffle furnace at a temperature of $400{ }^{\circ} \mathrm{C}$. It was baked for $4 \mathrm{~h}$, and then placed in a desiccator to be cooled to room temperature. Around $0.1-0.2 \mathrm{~g}$ of spilled oil samples were taken in a $15-\mathrm{mL}$ centrifuge tube, while $10 \mathrm{ml}$-hexane was added to them. The solutions were shaken for $15 \mathrm{~min}$ in an ultrasonic oscillator (DL-1800E). Then, $1 \mathrm{~g}$ anhydrous Na2SO4 was added to the centrifuge tubes and filtered with a nylon membrane filter. Afterwards, $350 \mu \mathrm{L}$ filtered samples were added to an Agilent bottle $(2 \mathrm{~mL})$. Finally, three $50 \mu \mathrm{L}$ internal standards $(10 \mathrm{~g} / \mathrm{mL})$ were added to the filtered samples, and $\mathrm{n}$-hexane was finally added to make the overall volume to be $1 \mathrm{~mL}$.

\section{Instruments and analytical conditions}

GC-MS analyses of these samples were performed using an Agilent 5973N-MSD instrument coupled with an Agilent 6890 GC system. The column was an HP-5MS capillary column (30 m, $0.25 \mathrm{~mm}, 0.25 \mu \mathrm{m}$; Agilent).

The gas chromatographic conditions were as follows: high-purity helium gas (purity $>99.99 \%$ ), column constant current $1 \mathrm{~mL} / \mathrm{min}$, injection volume $1 \mu \mathrm{L}$; inlet temperature $280{ }^{\circ} \mathrm{C}$, splitless injection, interface temperature $280{ }^{\circ} \mathrm{C}(16 \mathrm{~min})$ at a rate of $6{ }^{\circ} \mathrm{C}$ per minute, and the temperature was raised to $300{ }^{\circ} \mathrm{C}(16 \mathrm{~min})$ at a rate of $50{ }^{\circ} \mathrm{C}(2 \mathrm{~min})$.

The mass spectrometry conditions were as follows: electron impact ion source, interface temperature $280{ }^{\circ} \mathrm{C}$, ion source temperature $230^{\circ} \mathrm{C}$, electron energy $70 \mathrm{eV}$, quartile bar temperature $150{ }^{\circ} \mathrm{C}$, solvent delay 4 min, selecting ion scan mode.

The results of the analyses of the samples were the average of the repeated measurements with an $\mathrm{RSD}< \pm 5 \%$. The 
multi-point calibration curve and internal standard method were used as the quantitative methods.

\section{Gas chromatography-thermal conversion/thermal cracking furnace and isotope mass spectrometry}

The determination of the carbon isotope composition of individual $n$-alkanes was carried out at the Key Laboratory of Petroleum Resources Research, Institute of Geology and Geophysics, Chinese Academy of Sciences, Lanzhou, China.

\section{Reagents and sample preparation}

The standing oil spill and chloroform asphalt were filtered through a filter paper using a funnel. The filtrates were mixed with the saturated hydrocarbon, aromatic hydrocarbon, and non-hydrocarbon. The asphaltenes were obtained with methylene chloride, air-dried in air, and washed with $60 \mathrm{~mL}$ petroleum ether-leaching solution. The saturated hydrocarbon components were washed with $40 \mathrm{~mL}$ of methylene chloride: petroleum ether $(2: 1 v / v)$ mixture, which washed the aromatic hydrocarbon components, whereas the non-hydrocarbon components were eluted with $30 \mathrm{~mL}$ of ethanol.

\section{Instruments and analytical conditions}

The carbon isotopes values of individual $n$-alkanes were determined using a combination of Trace GC (ThermoFisher Scientific, USA), thermal conversion/thermal cracking furnace (TC), and isotope mass spectrometer (Thermo Scientific MAT 253, Thermo-Fisher). The mass spectrometric conditions were as follows: $5.0 \times 10^{-7} \mathrm{MPa}$ for the foreline pump, $1.4 \times 10^{-10} \mathrm{MPa}$ for the ion source, EI for the ion source, $1.5 \mathrm{~mA}$ for the emission current, and $90 \mathrm{~V}$ for the electron energy. The receiver temperature was $270{ }^{\circ} \mathrm{C}$ to ensure complete gasification of the samples. In order to ensure complete cracking of the samples, the cracking furnace temperature was kept at $1480{ }^{\circ} \mathrm{C}$. A quartz capillary chromatographic column $(50 \mathrm{~m} \times 32 \mathrm{~mm} \times 25 \mu \mathrm{m})$ was used. The carrier gas was high-purity helium (99.999\%). Further conditions were as follows: constant current mode $(1.2 \mathrm{~mL} / \mathrm{min})$ with less splitting injection. Column temperature program: the initial temperature of $80^{\circ} \mathrm{C}$ was maintained for $5 \mathrm{~min}$. The temperature was raised to $300{ }^{\circ} \mathrm{C}$ at a rate of $3{ }^{\circ} \mathrm{C} / \mathrm{min}$ and maintained for $30 \mathrm{~min}$.

The samples are first separated into individual compounds by gas chromatography, followed by pyrolysis in a cracking furnace at elevated temperature and then conversion to hydrogen and elemental carbon. Finally, the elemental carbon entered the mass Ispectrometer for the analysis of isotopic composition of the compounds ( $\mathrm{Li}$ et al. 2007). Under normal circumstances, good chromatographic separation is a prerequisite to ensure the experimental results. Additionally, complete cracking of alkanes is a significant factor affecting the analysis results. For mass spectrometry, the stability and accuracy of data quality play a decisive role (Wang et al. 2016). The results were compared according to the VPBD criteria. Each sample has passed repeat tests, whereas the data shown are the averages of the test data. The deviation error for each compound is less than $0.5 \%$.

\section{Results and discussion}

Significant changes in the short-term weathering trend of the PAHs' diagnostic index for oil spills are characterized by mixed-source oil or mixed oil spills. Because of the low detection rate of PAHs, this study did not analyze and discuss relative diagnosis indicators of PAHs. The numbering system and the values of different diagnostic ratios are listed in Table 1.

\section{Weathering characteristics of saturated hydrocarbon indicators}

The pattern of GC-MS saturated hydrocarbons of oil samples collected from one oil spill cannot give information about the specific type of the oil sample. If there is a similar pattern with the suspected oil source, it can only judge the suspected oil source as one of the oil end members; however, it cannot confirm that the oil spill completely came from the suspected oil source (He et al. 2014a). Using the fingerprint distribution characteristics of saturated hydrocarbon to identify oil source is a method of oil spill identification, though it is difficult to detect the phenomenon of oil mixing and even the different classification of miscellaneous spilled oils.

The GC-MS mass chromatograms $(\mathrm{m} / \mathrm{z} 85)$ of the saturated hydrocarbons in the Dalian spill oil (Fig. 1) shows that the initial $n$-alkane content of $n$ - $\mathrm{C}_{8} \sim n-\mathrm{C}_{36}$ in the initial oil spill sample is higher than others (DL-1). The highest abundance values ranged from $n-\mathrm{C}_{10}$ to $n-\mathrm{C}_{18}$ and from $n-\mathrm{C}_{27}$ to $n-\mathrm{C}_{31}$, whereas the abundance of $n-\mathrm{C}_{12}$ was the highest and that of the $n-\mathrm{C}_{21}$ was the lowest. With the increase in the degree of weathering, the saturated hydrocarbon content of the oil spill gradually decreased. After 120 days of the weathering process, the residual oil's (DL6) saturated hydrocarbon content of $n-\mathrm{C}_{8} \sim n-\mathrm{C}_{13}$ of Dalian oil spill disappeared. Thereafter, lower-molecular-weight alkanes (LMW) were affected by the biodegradation as compared to the higher-molecular-weight (HMW) alkanes. The LMW/ HMW values of the weathered residual oil were lower than those of the initial oil (Fig. 2).

The diagnostic ratios of some low-molecular-weight components, such as $\mathrm{Pr} / \mathrm{Ph}, \mathrm{Pr} / n-\mathrm{C}_{17}, \mathrm{Ph} / n-\mathrm{C}_{18}$, and carbon preference index (CPI), are mainly used to identify the unweather 
Table 1 Selected diagnostic ratios used for source identification of the Dalian oil spill

\begin{tabular}{|c|c|c|c|c|c|c|}
\hline \multirow[t]{2}{*}{ Diagnosis ratios } & \multicolumn{6}{|c|}{ Sample ID } \\
\hline & DL-1 & DL-2 & DL-3 & DL-4 & DL-5 & DL-6 \\
\hline $\mathrm{Pr} / \mathrm{Ph}^{\mathrm{a}}$ & 1.22 & 1.70 & 1.12 & 1.44 & 1.73 & 1.70 \\
\hline $\mathrm{Pr} / n-\mathrm{C}_{17}{ }^{\mathrm{b}}$ & 1.52 & 1.82 & 1.77 & 1.98 & 2.59 & 6.30 \\
\hline $\mathrm{Ph} / n-\mathrm{C}_{18}{ }^{\mathrm{c}}$ & 1.43 & 1.25 & 1.93 & 1.59 & 1.27 & 1.68 \\
\hline$(\mathrm{C} 13+\mathrm{C} 14) /(\mathrm{C} 25+\mathrm{C} 26)^{\mathrm{d}}$ & 1.34 & 0.62 & 1.31 & 1.43 & 0.71 & 0.63 \\
\hline LMW/HMW & 0.97 & 0.46 & 1.37 & 1.11 & 0.86 & 0.88 \\
\hline $\mathrm{CPI}_{1}{ }^{\mathrm{f}}$ & 0.95 & 0.97 & 1.04 & 1.21 & 1.17 & 1.30 \\
\hline $\mathrm{CPI}_{2}{ }^{\mathrm{g}}$ & 0.95 & 1.08 & 1.06 & 0.93 & 0.82 & 0.78 \\
\hline $\mathrm{OEP}_{1}{ }^{\mathrm{h}}$ & 0.91 & 0.89 & 1.06 & 1.03 & 0.73 & 1.08 \\
\hline $\mathrm{OEP}_{2}{ }^{\mathrm{i}}$ & 1.19 & 1.00 & 1.07 & 1.40 & 1.31 & 1.71 \\
\hline $\mathrm{Ts} / \mathrm{Tm}^{\mathrm{j}}$ & 0.29 & 0.36 & 0.29 & 0.29 & 0.30 & 0.36 \\
\hline $\mathrm{C} 29 \mathrm{a} \beta / \mathrm{C} 30 \mathrm{a} \beta^{\mathrm{k}}$ & 0.73 & 0.68 & 0.73 & 0.73 & 0.73 & 0.68 \\
\hline $\mathrm{C} 30 \beta \mathrm{a} / \mathrm{C} 30 \mathrm{a} \beta^{1}$ & 0.13 & 0.15 & 0.13 & 0.13 & 0.14 & 0.15 \\
\hline $\mathrm{C} 31 \mathrm{~S} /(\mathrm{S}+\mathrm{R})^{\mathrm{m}}$ & 0.55 & 0.56 & 0.55 & 0.56 & 0.56 & 0.56 \\
\hline $\mathrm{H} 32 \mathrm{~S} /(\mathrm{S}+\mathrm{R})^{\mathrm{n}}$ & 0.58 & 0.58 & 0.58 & 0.58 & 0.59 & 0.58 \\
\hline $\mathrm{C} 33 \mathrm{~S} /(\mathrm{S}+\mathrm{R})^{\mathrm{o}}$ & 0.58 & 0.56 & 0.58 & 0.58 & 0.58 & 0.56 \\
\hline $\mathrm{C} 27 / \mathrm{C} 29^{\mathrm{p}}$ & 1.37 & 1.29 & 1.39 & 1.29 & 1.41 & 1.29 \\
\hline $\mathrm{C} 29 \beta \beta /(\alpha \alpha+\beta \beta)^{\mathrm{q}}$ & 0.41 & 0.41 & 0.42 & 0.41 & 0.41 & 0.41 \\
\hline $\mathrm{C} 29 \mathrm{~S} /(\mathrm{S}+\mathrm{R})^{\mathrm{r}}$ & 0.38 & 0.51 & 0.40 & 0.51 & 0.42 & 0.51 \\
\hline
\end{tabular}

${ }^{\text {a }}$ Pristane to Phytane

${ }^{\mathrm{b}}$ Pristane to $n-\mathrm{C}_{17}$ alkane

${ }^{\mathrm{c}}$ Phytane to $n-\mathrm{C}_{18}$ alkane

${ }^{\mathrm{d}} n$-Alkanes $\left(n-\mathrm{C}_{13}+n-\mathrm{C}_{14}\right) /\left(n-\mathrm{C}_{25}+n-\mathrm{C}_{26}\right)$

${ }^{\text {e }}$ Ratio of sum of $n-\mathrm{C}_{14}$ to $n-\mathrm{C}_{21}$ alkanes to sum of $n-\mathrm{C}_{22}$ to $n-\mathrm{C}_{34}$ alkanes

${ }^{\mathrm{f}} 1 / 2\left[\left(n-\mathrm{C}_{15}+n-\mathrm{C}_{17}+n-\mathrm{C}_{19}+n-\mathrm{C}_{21}+n-\mathrm{C}_{23}\right) /\left(n-\mathrm{C}_{14}+n-\mathrm{C}_{16}+n-\mathrm{C}_{18}+n-\mathrm{C}_{20}+n-\mathrm{C}_{22}\right)+\left(n-\mathrm{C}_{15}+n-\mathrm{C}_{17}+n-\mathrm{C}_{19}+n-\mathrm{C}_{21}+n-\mathrm{C}_{23}\right) /\left(n-\mathrm{C}_{16}+n-\mathrm{C}_{18}+n-\mathrm{C}_{20}+n-\right.\right.$ $\left.\left.\mathrm{C}_{22}+n-\mathrm{C}_{24}\right)\right]$

${ }^{\mathrm{g}} 1 / 2\left[\left(n-\mathrm{C}_{25}+n-\mathrm{C}_{27}+n-\mathrm{C}_{29}+n-\mathrm{C}_{31}+n-\mathrm{C}_{33}\right) /\left(n-\mathrm{C}_{24}+n-\mathrm{C}_{26}+n-\mathrm{C}_{28}+n-\mathrm{C}_{30}+n-\mathrm{C}_{32}\right)+\left(n-\mathrm{C}_{25}+n-\mathrm{C}_{27}+n-\mathrm{C}_{29}+n-\mathrm{C}_{31}+n-\mathrm{C}_{33}\right) /\left(n-\mathrm{C}_{26}+n-\mathrm{C}_{28}+n-\mathrm{C}_{30}+n-\right.\right.$ $\left.\left.\mathrm{C}_{32}+n-\mathrm{C}_{34}\right)\right]$

${ }^{\mathrm{h}} n$-Alkanes $\left(n-\mathrm{C}_{17}+6 \times n-\mathrm{C}_{19}+n-\mathrm{C}_{21}\right) /\left(4 \times n-\mathrm{C}_{18}+4 \times n-\mathrm{C}_{20}\right)$

${ }^{\mathrm{i}} n$-Alkanes $\left(n-\mathrm{C}_{21}+n-6 \times n-\mathrm{C}_{23}+n-\mathrm{C}_{25}\right) /\left(4 \times n-\mathrm{C}_{10}+4 \times n-\mathrm{C}_{24}\right)$

${ }^{\mathrm{j}}$ Ratio of $18 \alpha-22,29,30$-trisnorneohopane to $17 \alpha-22,29,30$-trisnorhopane

${ }^{\mathrm{k}}$ Ratio of to $17 \alpha(\mathrm{H}), 21 \beta(\mathrm{H})-29$-hopane to $17 \alpha(\mathrm{H}), 21 \beta(\mathrm{H})$-30-norhopane

${ }^{1}$ Ratio of $17 \beta(\mathrm{H}), 21 \alpha(\mathrm{H})-30$-moretane to $17 \alpha(\mathrm{H}), 21 \beta(\mathrm{H})$-30-norhopane

${ }^{\mathrm{m}}$ Ratio of $17 \alpha(\mathrm{H}), 21 \beta(\mathrm{H})-\mathrm{C}_{31}$-hopane (S) to sum of $17 \alpha(\mathrm{H}), 21 \beta(\mathrm{H})-\mathrm{C}_{31}$-hopane (S) and $17 \mathrm{a}(\mathrm{H}), 21 \mathrm{~b}(\mathrm{H})-\mathrm{C}_{31}$-hopane (R)

${ }^{\mathrm{n}}$ Ratio of $17 \alpha(\mathrm{H}), 21 \beta(\mathrm{H})-\mathrm{C}_{32}$-hopane (S)to sum of $17 \alpha(\mathrm{H}), 21 \beta(\mathrm{H})-\mathrm{C}_{32}$-hopane (S) and $17 \alpha(\mathrm{H}), 21 \beta(\mathrm{H})-\mathrm{C}_{32}$-hopane (R)

${ }^{\mathrm{o}}$ Ratio of $17 \alpha(\mathrm{H}), 21 \beta(\mathrm{H})-\mathrm{C}_{33}$-hopane (S)to sum of $17 \alpha(\mathrm{H}), 21 \beta(\mathrm{H})-\mathrm{C}_{33}$-hopane (S) and $17 \alpha(\mathrm{H}), 21 \beta(\mathrm{H})-\mathrm{C}_{33}$-hopane (R)

${ }^{\mathrm{p}}$ Ratio of sum of $5 \alpha(\mathrm{H}), 14 \alpha(\mathrm{H}), 17 \alpha(\mathrm{H})-\mathrm{C}_{27}$-steranes (S + R)and $5 \alpha(\mathrm{H}), 14 \alpha(\mathrm{H}), 17 \alpha(\mathrm{H})-\mathrm{C}_{27}$-steranes (S+ R) to sum of $5 \alpha(\mathrm{H}), 14 \alpha(\mathrm{H}), 17 \alpha(\mathrm{H})-\mathrm{C}_{29}{ }^{-}$ sterane $(\mathrm{S}+\mathrm{R})$ and $5 \alpha(\mathrm{H}), 14 \beta(\mathrm{H}), 17 \beta(\mathrm{H})-\mathrm{C}_{29}$-sterane $(\mathrm{S}+\mathrm{R})$

${ }^{\mathrm{q}}$ Ratio of $\mathrm{C}_{29} 5 \alpha(\mathrm{H}), 14 \beta(\mathrm{H}), 17 \beta(\mathrm{H})$-24-ethyl-cholestane $(20 \mathrm{~S}+20 \mathrm{R})$ to sum of Ratio of $\mathrm{C}_{29} 5 \alpha(\mathrm{H}), 14 \alpha(\mathrm{H}), 17 \alpha(\mathrm{H})$-24-ethyl-cholestane (20S + 20R), and $\mathrm{C}_{29} 5 \alpha(\mathrm{H}), 14 \beta(\mathrm{H}), 17 \beta(\mathrm{H})$-24-ethyl-cholestane (20S + 20R)

${ }^{\mathrm{r}}$ Ratio of $\mathrm{C}_{29} 5 \alpha(\mathrm{H}), 14 \alpha(\mathrm{H}), 17 \alpha(\mathrm{H})$-24-ethyl-cholestane $20 \mathrm{~S}$ to $\mathrm{C}_{29} 5 \alpha(\mathrm{H}), 14 \alpha(\mathrm{H}), 17 \alpha(\mathrm{H})$-24-ethyl-cholestane $(20 \mathrm{~S}+20 \mathrm{R})$

or weakly weathered oils which originate from a single source. However, these indices have limited capability about discriminating the medium and severity of the weathered oil spills. The results showed that, in the short-term weathering process, the degree of weathering of light components in the oil with more abundant light components were different.
It can be seen from Fig. 2 that the diagnostic ratios of LMW/HMW, $\mathrm{Pr} / \mathrm{Ph}, \mathrm{Ph} / n-\mathrm{C}_{18}$, and $\left(\mathrm{C}_{13}+\mathrm{C}_{14}\right) /\left(\mathrm{C}_{25}+\mathrm{C}_{26}\right)$ of 1-day weathering oil sample (DL-2) are different from the same ratio of the other oils, indicating that the oil sample of 1day weathering is significantly different from the other Dalian-spilled oils. This indicates that the Dalian oil sample 
Fig. 1 GC-MS chromatograms of aliphatic hydrocarbons from initial oils (a) and oil residue 120 days (b) after the spill happened in the Dalian Bay

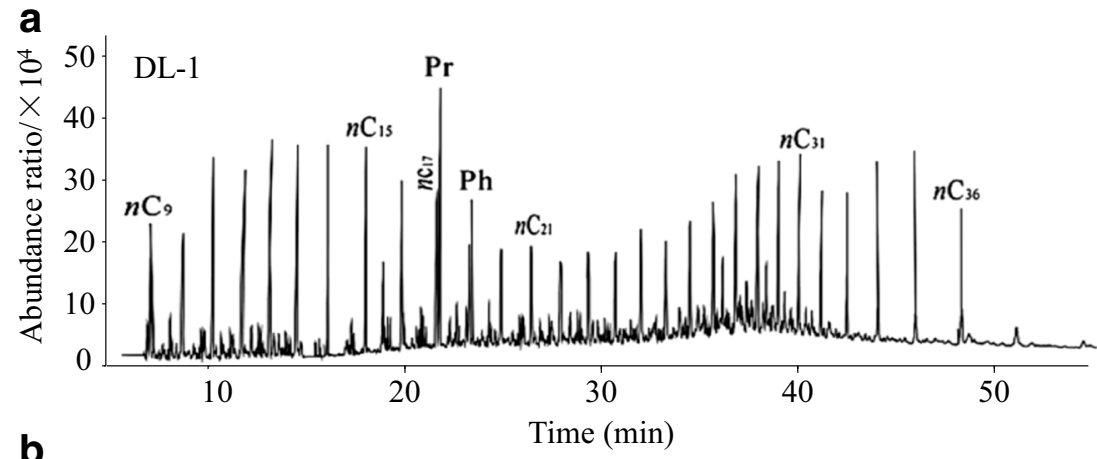

b

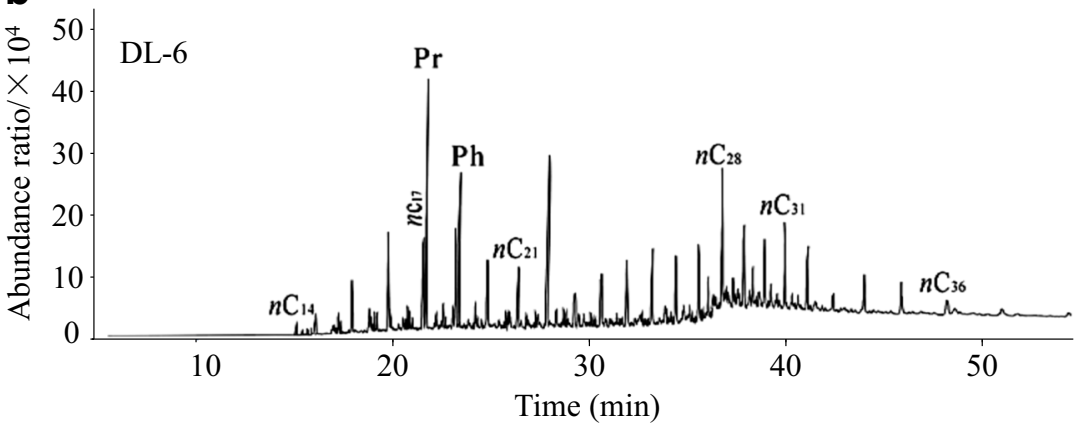

of 1-day weathering should have been mixed with another spilled crude oil or mixed with oils having saturated hydrocarbons with concentration comparatively different from the concentration (of saturated hydrocarbons) in the Dalian spilled oil. Furthermore, the mixed oil is not a mixture of the unweather Dalian spilled oil; rather, it is weakly weathered oil.

Most of $n$-alkane diagnostic ratios remain constant in the short-term weathering process and are appropriate for the identification of oil which is undergoing a short-term weathering process. Additionally, the tracing effect of these diagnostic ratios is not obvious in the long-term weathering process. If some severe oil process happened with one of end member oil passing through a severe weathering process, some diagnostic ratios, such as $\mathrm{Pr} / \mathrm{Ph}$, are not suitable for the

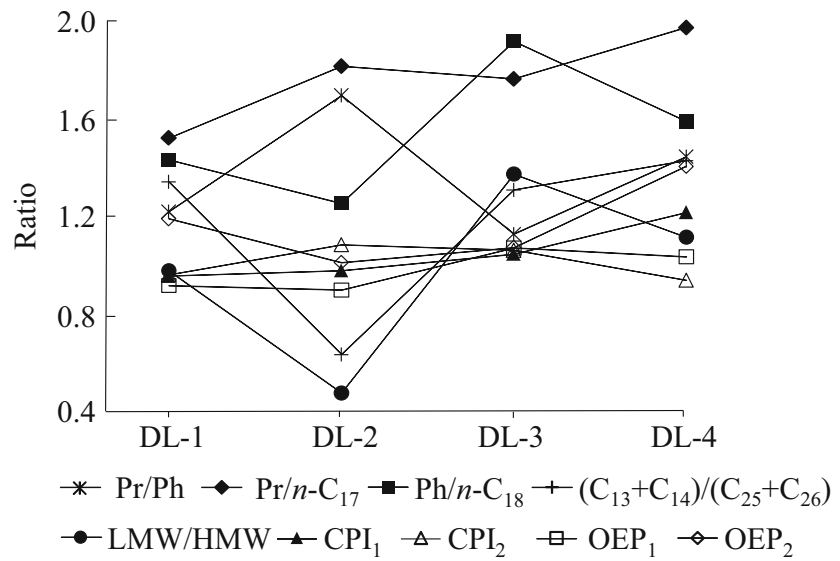

Fig. 2 Short-term changes of diagnosis parameters of $n$-alkanes and isoprenoid hydrocarbons in the Dalian spill oils short-term weathering of the oil spills. If there is a certain difference in the diagnostic ratios of several short-term samples collected at the oil spill site, especially at the marine oil spill site, an oil spill mixing process is likely to have taken place (Yim et al. 2011).

The correlation between $\mathrm{Pr} / n-\mathrm{C}_{17}$ and $\mathrm{Ph} / n-\mathrm{C}_{18}$ showed that the relationship between the ratio of $\mathrm{Pr} / n-\mathrm{C}_{17}$ and that of $\mathrm{Ph} / n$ $\mathrm{C}_{18}$ could be used to trace the intensity of the microbial action, sedimentary environment, parent material type, and degree of maturation (Shanmugam 1985; Peters and Moldowan 1993). It is obvious to state that for higher values of $\mathrm{Pr} / n-\mathrm{C}_{17}$ and $\mathrm{Ph} / n$ $\mathrm{C}_{18}$ ratios, the action of microorganisms is stronger, and vice versa (Formolo et al. 2008). The graph of $\mathrm{Pr} / n-\mathrm{C}_{17}$ against $\mathrm{Ph} /$ $n$ - $\mathrm{C}_{18}$ of the weathering oil with a single source should roughly be a straight line along the direction of the biodegradation ( $\mathrm{He}$ et al. 2014b). In this paper, the authors have used the $\operatorname{Pr} / n-\mathrm{C}_{17}$ and $\mathrm{Ph} / n-\mathrm{C}_{18}$ values as references as stated in Liu et al. (2012) for oil spill samples $(0,5$, and 9 days) and for oil spill samples $(0,15$, and 23 days). Figure 3 shows that the ratio spots of $\operatorname{Pr} / n$ $\mathrm{C}_{17}$ to $\mathrm{Ph} / n-\mathrm{C}_{18}$, as reported by Liu et al. (2012), fall approximately in a straight line parallel to the trend line of biodegradation. The difference between $\operatorname{Pr} / n-\mathrm{C}_{17}$ and $\mathrm{Ph} / n-\mathrm{C}_{18}$ was small, which indicated that there was a correlation between the series of Dalian oil spill samples collected by Liu et al. (2012), which also experienced some degree of weathering. It can also be seen that the weathering speed of the oil samples collected from the sea surface of the Dalian Bay was faster than for the oil spills collected along the shore of the Dalian Bay.

The distribution of $\mathrm{Pr} / n-\mathrm{C}_{17}$ and $\mathrm{Ph} / n-\mathrm{C}_{18}$ of four shortterm weathered Dalian oil spill samples is scattered and 


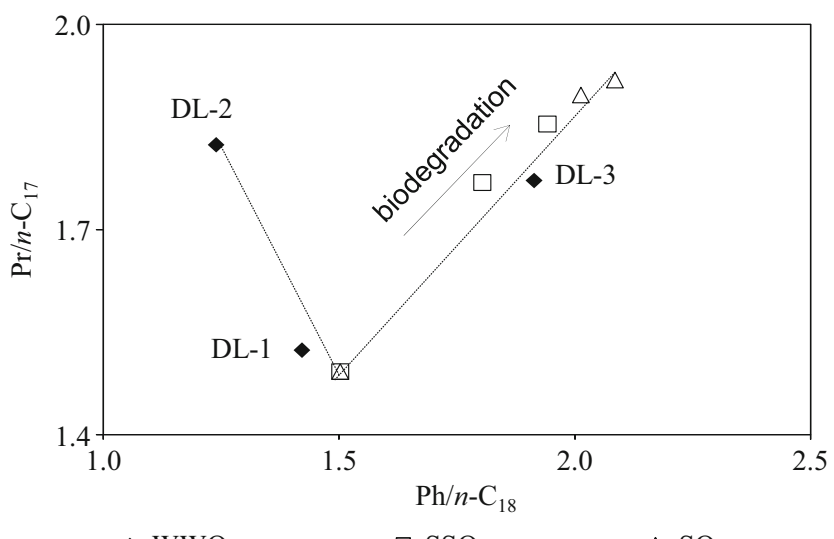

- WWO

$\square \mathrm{SSO}$

$\triangle \mathrm{SO}$

Fig. 3 Isoprenoids plot of $\mathrm{Ph} / n-\mathrm{C}_{18}$ vs. $\mathrm{Pr} / n-\mathrm{C}_{17}$ in the Dalian spill oils. Wake weathered oil samples (WWO) were sampled by our work. Sea surface and stranded oil samples (SSO and SO) were collected by Liu et al. (2012)

Idoes not represent a straight line, indicating a low correlation for the oil samples. The ratios of $\mathrm{Pr} / n-\mathrm{C}_{17}$ and $\mathrm{Ph} / n-\mathrm{C}_{18}$ for DL-1 and DL-3 are roughly in line with those of the oil spill samples collected from the sea surface and the heavy oilcontaminated area of the beach analyzed by Liu et al. (2012). It is worth mentioning that the scattered plots of $\mathrm{Pr} /$ $n-\mathrm{C}_{17}$ and $\mathrm{Ph} / n-\mathrm{C}_{18}$ of DL- 2 were different from others. The results showed that there were obvious differences between DL-2 and other Dalian oil spill samples (e.g., DL-3, DL-4, DL-5, and DL-6), which suggested that DL-2 may be mixed or a different oil from another single-source oil.

The standard deviation of the $n$-alkanes index is a manifestation of the mixed oil spill, and the RSD\% of some diagnostic ratios over 5\% is a manifestation of the mixed oil spill (He et al. 2015). From the RSD\% values of the $n$-alkanes in the Dalian oil spill samples (Fig. 4), it can be found that only the RSD\% of $\mathrm{CPI}_{1}$ is less than $5 \%$ in all the diagnostic ratios of short-term weathered Dalian oil spills, indicating that the stability of the diagnosis of Dalian short-term weathering oil spill is low.

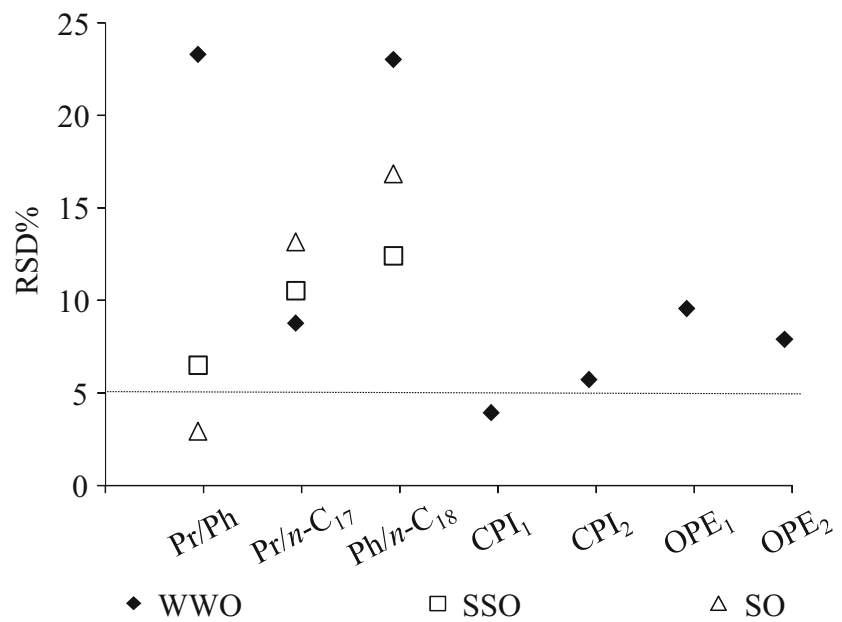

Fig. 4 RSD\% of conventional diagnosis parameters of Dalian oil samples

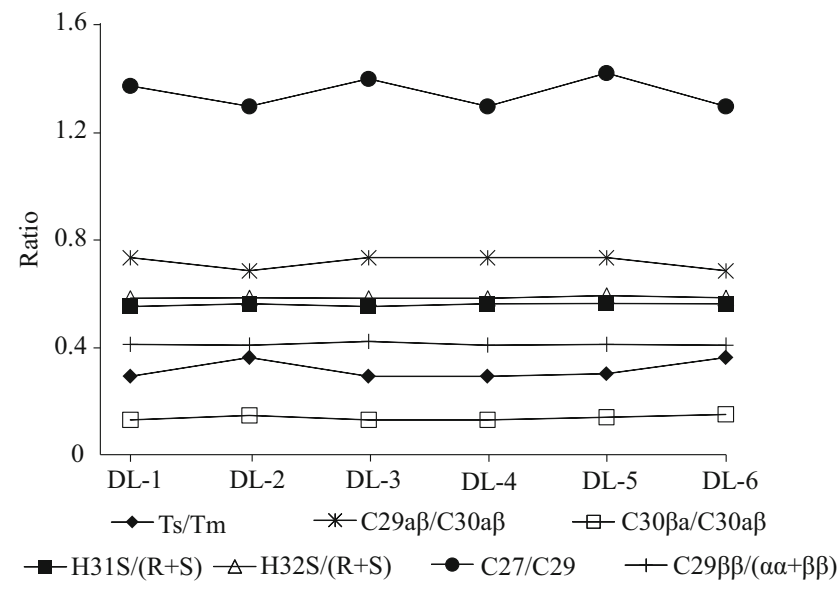

Fig. 5 Change modes of diagnostic ratios of terpanes and steranes in the Dalian spill oils

Only the standard deviation of $\mathrm{Pr} / \mathrm{Ph}$ for oil spill is less than $5 \%$, which can be linked to incomplete mixing of the oil spills, as suggested by Liu et al. (2012).

\section{Characteristics of steranes and terpanes indicators}

Both the steranes and terpanes are not readily influenced by the weathering process in comparison to $n$-alkanes. Their mass reduction is very low even after undergoing a moderate to severe weathering process. It indicates that some ratios of the steranes and terpanes can be used to trace the weathered oil source, especially the moderate to severely weathered oil. In this work, some commonly used diagnostic ratios of steranes and terpanes were selected (Table 1).

Figure 5 shows that the enumerative diagnostic ratios of steranes and terpanes in the Dalian oil spill (except C29 $\alpha \beta /$ $\mathrm{C} 30 \alpha \beta$ and $\mathrm{Ts} / \mathrm{Tm}$ ) remained almost constant throughout the weathering process, suggesting that the effect of the

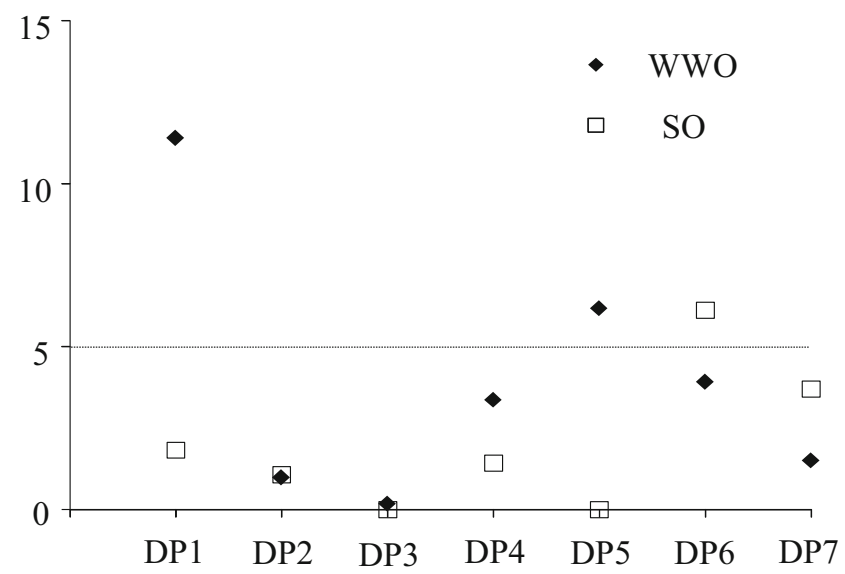

Fig. 6 RSD\% of conventional common diagnostic terpanes and steranes. DP1: Ts/Tm; DP2: $\mathrm{C}_{31} 22 \mathrm{~S} /(22 \mathrm{~S}+22 \mathrm{R}) ; \mathrm{DP} 3: \mathrm{C}_{32} 22 \mathrm{~S} /(22 \mathrm{~S}+22 \mathrm{R})$; DP4: $\mathrm{C}_{29} \alpha \beta / \mathrm{C}_{30} \alpha \beta$; DP5: $\mathrm{C}_{30} \beta \alpha / \mathrm{C}_{30} \alpha \beta$; DP6: $\mathrm{C}_{27} / \mathrm{C}_{29}$; DP7: $\mathrm{C}_{29} \beta \beta /$ $(\beta \beta+\alpha \alpha)$ 
weathering process on the ratios of steranes and terpanes was limited. Moreover, the weathering change of these indices except C27/C29 indicate that the Dalian oil spill does not have the obvious characteristics of oil undergoing the mixing process, which is different from the characteristics reflected through the ratios of $n$-alkanes. The fact that the $\mathrm{C} 27 / \mathrm{C} 29$ change mode exhibits a "zigzag" pattern indicates that there was a mixing process that influenced some ratios of steranes and terpanes.

The standard deviation of the diagnostic ratios for steranes and terpanes is high when mixed oils are not well mixed, which can ultimately influence the standard deviation of the diagnostic ratios of steranes and terpanes from the mixed spilled oils (He et al. 2015). In general, multiple indicators of marine fuel oil with multi-sources show the characteristics of larger standard deviation, which is not related to the weathering stability of the indicators but may be the result of the mixing process (Sun and Ma 2014). The stability of $\mathrm{H} 31 \mathrm{~S} /(\mathrm{R}+\mathrm{S})$ and $\mathrm{H} 32 \mathrm{~S} /(\mathrm{R}+\mathrm{S})$ in all types of oil spill identification is strong.

It can be found from Fig. 6 that the RSD\% of ratios of steranes and terpanes (except $\mathrm{Ts} / \mathrm{Tm}$ trinorhopane and $\mathrm{C} 30 \beta \alpha / \mathrm{C} 30 \alpha \beta$ ) were less than $5 \%$ in 210 days of the weathering process. The $\mathrm{RSD} \%$ values of the $\mathrm{C} 27 / \mathrm{C} 29$ and $\mathrm{C} 29 \beta \beta /(\alpha \alpha+\beta \beta)$ were more than $5 \%$ of the diagnostic ratios of steranes and terpanes in the samples collected from the oil-polluted seashore of the Dalian Bay by Liu et al. (2012). Overall, only few ratios of steranes and terpanes in different oil samples showed lower stability, which did not agree to the theory that the Dalian oil spill has the characteristics of the mixing of oils. In other words, the difference in the indices of steranes and terpanes in the Dalian oil spill from different periods is small, indicating that the oil samples emerged from the same single-source oil.

\section{Characteristics of carbon isotope composition of $n$-alkanes}

Due to the progress made in detection technology of stable isotopes, carbon isotope values of individual organic compounds have been measured using gas chromatograph/isotope ratio mass spectrometer (GC-IRMS). GC-IRMS has the capability of carrying out compound-specific isotope analysis (CSIA), which is one of the most powerful techniques in the molecular isotope studies, and allows the determination of the stable isotopic ratios in the individual chemical species occurring in the complex mixtures. CSIA can overcome some of the limitations of carbon isotope applications in the oil sector (Slater et al. 1999; Hunkeler et al. 1999; Ferlian et al. 2014; Bashir et al. 2015). Using carbon isotope composition of individual compounds to identify the oil source, it is generally based on the similarity of distribution curves of carbon isotopes of individual $n$-alkanes as the basis of the discrimination (Xiong et al. 2001; Wang et al. 2009; Ho et al. 2015).

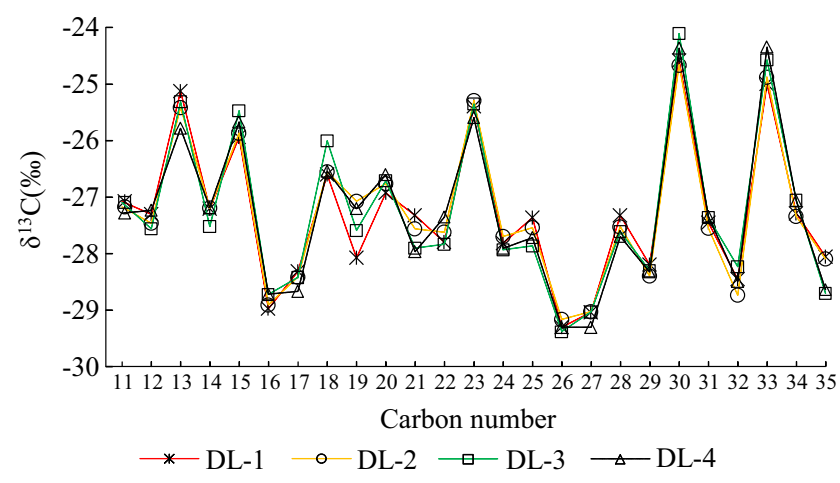

Fig. 7 Change modes of individual carbon isotopic composition of fractions in the Dalian spill oil samples

The distribution tendency of $\delta^{13} \mathrm{C}$ values of individual $n$ alkanes from the Dalian oil spill in different weathering periods is shown in Fig. 7. It can be observed that the distribution pattern of the carbon isotope $\delta^{13} \mathrm{C}$ in different weathering periods of the Dalian oil spill is very close to its initial distribution pattern. The standard deviation of $\delta^{13} \mathrm{C}$ values in 0 to 60 days is 0.07 to $0.20 \%$, while the standard deviation of $\delta^{13} \mathrm{C}$ values in 0 to 90 days is 0.06 to $0.36 \%$. The carbon isotope $\delta^{13} \mathrm{C}$ values of individual $n$-alkanes (except $n$-C $\mathrm{C}_{19}$ ) changed slightly, indicating that the isotopic fractionation of $n$-alkanes in the Dalian oil spill was not significant during the whole weathering period. Therefore, the weathering process had no obvious effect on the carbon isotope values of all the individual $n$-alkanes. This means that there is no noticeable oil mixing process during the whole weathering period only through the proof of isotopic fractionation of $n$-alkanes in the Dalian oil spill; however, some other evidences of the Dalian spill oil (e.g., $n$-alkane diagnostic ratios) show an opposite effect.

A comprehensive analysis of the consequences of the Dalian oil spill and its weathered oil are required and can be considered. The results showed that the spill oil came from a single source and did not involve meaningful oil mixing process. After being spilled into the marine environment, the $n$-alkanes index of the Dalian oil spill was disturbed by some kinds of $n$-alkanerich substance. The mixed materials were difficult to be stored within the water environment. Hence, the impact of the mixed materials on the Dalian oil spill indicators was less than 10 days. Liu et al. (2010) confirmed that the typical oil dispersants rich in $n$-alkanes cause an easy change in the $n$-alkane-related identification ratios.

\section{Conclusion}

The results indicated that the weathering characteristics of the $n$ alkane ratios of the Dalian oil spill were distinct from those of steranes, terpenes, and carbon isotope compostion of individual $n$-alkanes. After the oil was spilled into the environment, some $n$ alkane-rich oils (such as oil dispersants) mixed with the oil and 
influenced the $n$-alkane indicators. The main period of the disturbance of $n$-alkane index occurred at the early stage of the oil spill weathering process. To determine whether an oil spill was mixed or not, the characteristics of a variety of indicators need to be taken into consideration, which help in establishing a comprehensive analysis.

Funding information This work was financially supported by the National Natural Science Foundation of China (Grant No. 41206089) and the "1-3-5" Research Program of Yantai Institute of Coastal Zone Research, Chinese Academy of Sciences (Nos. Y254021031 and Y455011031).

\section{References}

Bashir S, Hitzfeld KL, Gehre M et al (2015) Evaluating degradation of hexachlorcyclohexane $(\mathrm{HCH})$ isomers within a contaminated aquifer using compound-specific stable carbon isotope analysis (CSIA)[J]. Water Res 71:187-196

Betti M, Boisson F, Eriksson M et al (2011) Isotope analysis for marine environmental studies[J]. Int J Mass Spectrom 307:192-199

Brandvik P J, Sørheim K R, Singsaas I et al (2006) Short state-of-the-art report on oil spills in ice-infested waters. SINTEF Materials and Chemistry. Report No. STF80MKA06148: 1-63

Christensen JH, Tomasi G (2007) Practical aspects of chemometrics for oil spill fingerprinting[J]. J Chromatogr A 1169(1-2):1-22. https:// doi.org/10.1016/j.chroma.2007.08.077

Ferlian O, Cesarz S, Marhan S et al (2014) Carbon food resources of earthworms of different ecological groups as indicated by $13 \mathrm{C}$ compound-specific stable isotope analysis[J]. Soil Biol Biochem 77:22-30

Fingas MF (2015) Handbook of oil spill science and technology[M]. John Wiley and Sons, Hoboken

Formolo M, Martini A, Petsch S (2008) Biodegradation of sedimentary organic matter associated with coalbed methane in the Powder River and San Juan basins, USA[J]. Int J Coal Geol 76(1):84-97

Goldstein BD, Osofsky HJ, Lichtveld MY (2011) The gulf oil spill[J]. New Engl J Med 364:1334-1348

Guo ZP (2004) The prevention and control of oil pollution of China's coastal waters[J]. J Zhejiang Ocean Univ (Nat Sci) 23(3):269-272 (In Chinese)

Guo J, Liu X, Xie Q (2013) Characteristics of the Bohai Sea oil spill and its impact on the Bohai Sea ecosystem[J]. Sci Bull 58(19):22762281

Hayworth JS, Clement PT, John GF et al (2015) Fate of deepwater horizon oil in Alabama's beach system: understanding physical evolution processes based on observational data[J]. Mar Pollut Bull 90: 95-105

He SJ, Wang CY, Han B et al (2014a) Effect of short-term weathering on mixtures with two different mixing oils[J]. Mar Sci 38(12):69-77 (In Chinese)

He SJ, Wang CY, Yu HJ et al (2014b) Study of indicators for identifying moderate and heavy weathering processes of diesel oils[J]. Mar Sci 38(1):27-32 (In Chinese)

He SJ, Wang CY, Han B et al (2015) Effect of short time weathering on biomarker ratios of terpanes, steranes and PAHs in two different mixing oils[J]. Haiyang Xuebao 37(2):1-10 (In Chinese)
Ho SJ, Wang CY, Wang M et al (2015) Effect of petroleum on carbon and hydrogen isotopic composition of long-chain n-alkanes in plants from the Yellow River Delta, China[J]. Environ Earth Sci 74(2): 1603-1610

Hunkeler D, Aravena R, Butler BJ (1999) Monitoring microbial dechlorination of tetrachloroethene (PCE) in groundwater using compound-specific stable carbon isotope ratios: microcosm and field studies[J]. Environ Sci Technol 33(16):2733-2738. https:// doi.org/10.1021/es981282u

ITOPF (2016) Downward trend in tanker spills continues[BE]. http:// www.itopf.com/news-events/news/article/downward-trend-intanker-spills-continues

Kvenvolden KA, Hostettler FD, Carlson PR et al (1995) Ubiquitous tar balls with a California source signature on the shorelines of Prince William sound, Alaska[J]. Environ Sci Technol 29(10):2684-2694

Li ZP, Li LW, Du L et al (2007) Applications of isotope ratio mass spectometers in geochemical research field[J]. China Meas Technol 33(5):14-16 87. (In Chinese)

Liu X, Wang Z, Ma XD et al (2010) Influence of typical dispersants on the effectiveness of biomarkers of oil spills[J]. Environ Chem 29(2): 299-304 (In Chinese)

Liu X, Zhang RR, Yao X et al (2012) Weathered regulation of oil spilled in actual environment[J]. Mar Environ Sci 31(5):686-691 (In Chinese)

Liu X, Meng R, Xing Q, Lou M, Chao H, Bing L (2015) Assessing oil spill risk in the Chinese Bohai Sea: a case study for both ship and platform related oil spills[J]. Ocean Coast Manag 108:140-146. https://doi.org/10.1016/j.ocecoaman.2014.08.016

Peters KE, Moldowan JM (1993) The biomarker guide: interpreting molecular fossils in petroleum and ancient sediments[M]. Prentice Hall, Englewood Cliffs

Shanmugam G (1985) Significance of coniferous rain forests and related organic matter in generating commercial quantities of oil, Gippsland Basin, Australia[J]. AAPG Bull 69(8):1241-1254

Slater GF, Dempster HS, Lollar BS et al (1999) Headspace analysis: a new application for isotopic characterization of dissolved organic contaminants[J]. Environ Sci Technol 32:190-194

Sun F, Ma QM (2014) Impact on composition and fingerprint characteristics in ship fuel oil of weathering process[J]. Mar Environ Sci 33(1):83-88 (In Chinese)

Wang CY, Che GM, Sheng YQ et al (2009) Application of carbon isotope in oil spill identification[J]. Environ Pollut Cont 31(7):21-24 (In Chinese)

Wang XB, Li ZP, Zhang MJ et al (2016) Compound-specific hydrogen isotope analysis for trace hydrocarbons in natural gas by using solid phase micro-extraction coupled to gas chromatography-isotope ratio mass spectrometry[J]. Nat Gas Geosci 6:1084-1091 (in Chinese)

Wei L, Hu L, Dong L et al (2014) A damage assessment model of the oil spill accident combining historical data and satellite remote sensing information: a case study in Penglai, 19-3 oil spill accident in China[J]. Mar Pollut Bull 91(1):258-271. https://doi.org/10.1016/j. marpolbul.2014.11.036

Xiong YQ, Geng AS, Sheng GY et al (2001) Characteristics of carbon isotopic composition of n-alkanes during hydrocarbon generation and expulsion and its significance[J]. Acta Sedimentol Sin 19(3): 469-473 (In Chinese)

Yim UH, Ha SY, An JG et al (2011) Fingerprint and weathering characteristics of stranded oils after the Hebei Spirit oil spill[J]. J Hazard Mater 197(15):60-69 